\title{
A construção do outro nas edições e traduções da obra de Carolina Maria de Jesus
}

\author{
The construction of an Other in the editions and translations \\ of the work of Carolina Maria de Jesus \\ La construcción del otro en las ediciones y traducciones \\ de la obra de Carolina Maria de Jesus
}

Ana Cláudia dos Santos São Bernardo*

\section{Resumo}

Este artigo investiga como as diferentes traduções e edições da obra da escritora afro-brasileira Carolina Maria de Jesus foram usadas para compor uma imagem específica do Brasil da década de 1960 para audiências estrangeiras. Nesse sentido, debate o poder da representação bem como de suas manipulações no processo de publicação sobre o qual certos autores têm capacidade de decisão limitada. Para tanto, comparo as estratégias de edição e tradução utilizadas em Quarto de despejo (1960) e na tradução feita por David St. Clair intitulada Child of the dark (1962) às estratégias usadas em Meu estranho diário (1996) e The unedited diaries of Carolina Maria de Jesus (1998), traduzido por Nacy P.S. Naro e Cristina Mehrtens. Intersecções de gênero, raça e classe são vistas nesta análise como elementos-chave na projeção internacional de Carolina Maria de Jesus. Discuto tradução como um instrumento autorizando certas representações e endossando o alcance político de artefatos culturais.

Palavras-chave: tradução, teoria pós-colonial, raça, história, Carolina Maria de Jesus.

\begin{abstract}
This article investigates how translations and different editions of the Afro-Brazilian writer Carolina Maria de Jesus' journals were used to construct a specific image of 1960s Brazil for a foreign audience. This article debates the power of representation not only by authors but also by editors, publishers, and translators, that is to say the entire publication process, which often limits authors' decision-making powers. I compare the edition and translation strategies used by Audálio Dantas in the publication of Quarto de despejo (1960) and by David St. Clair in the translation Child of the dark (1962) to the strategies used in Meu estranho diário (1996), translated as The unedited diaries of Carolina Maria de Jesus (1998) by Nancy P.S. Naro e Cristina Mehrtens. In this analysis, intersections of race, gender, and class are fundamental to the international portrayal of De Jesus. I discuss translation as the tool for making these constructions possible, as well as their political reach.
\end{abstract}

Keywords: translation, postcolonial translation, race, history, Carolina Maria de Jesus.

\section{Resumen}

Este artículo investiga cómo las diferentes traducciones y ediciones de la obra de la escritora afro-brasileña Carolina Maria de Jesus fueron usadas para componer una imagen específica del Brasil de los años 1960 para audiencias extranjeras. El presente artículo debate el poder de la representación así como de sus manipulaciones en el proceso de publicación sobre el que ciertos autores tienen capacidad de decisión limitada. Para tanto, comparo las estrategias de edición y traducción utilizadas en Quarto de despejo (1960) y en la traducción hecha por David St. Clair titulada Child of the dark (1962) a las estrategias usadas en $\mathrm{Meu}$ estranho diário (1996) y The unedited diaries of Carolina Maria de Jesus (1998), traducida por Nacy PS Naro y Cristina Mehrtens. Las intersecciones de género, raza y clase se ven en este análisis como elementos clave en la proyección internacional de Carolina María de Jesús. Discuto la traducción como un instrumento que autoriza ciertas representaciones y endosa el alcance político de los artefactos culturales.

Palabras clave: traducción, teoría post-colonial, raza, historia, Carolina Maria de Jesus.

\footnotetext{
* Doutoranda na área de estudos culturais em espanhol e português no Departament of Spanish and Portuguese Studies, University of Minnesota, Minneapolis, MN, Estados Unidos. (Dorcid.org/0000-0002-2693-3795. E-mail: saobe001@umn.edu
} 


\section{Texto em contexto}

Os estudos de tradução sob o ponto de vista das críticas pós-coloniais reconhecem o traço colonizador das traduções ao mesmo tempo em que acreditam também nos benefícios que conhecer outras sociedades e suas produções culturais e intelectuais pode trazer. O impasse maior está em como e por que esses conhecimentos são transportados e utilizados. Geralmente, eles são disseminados por mercados editoriais que beneficiam pensamentos hegemônicos locais. Traduções podem se tornar instrumentos que permitem a apropriação de capital cultural estrangeiro.

Longe de criar uma teoria da conspiração ou mesmo uma contribuição para a demonização da tradução, esse ensaio alerta para o perigo de traduções que ignoram contexto e impactos do movimento entre cultura de chegada e cultura de saída. Além disso, problematizo traduções que objetivam "transparência." Este é o caso da tradução de Quarto de despejo, produzida por David St. Clair (1932-1991) e publicada em 1962 sob o título de Child of the dark e a tradução de Meu estranho diário (1996), de Carolina Maria de Jesus, por Nancy P. S. Naro e Cristina Mehrtens sob o título de The unedited diaries of Carolina Maria de Jesus, publicada em 1999, que são os focos desta análise. Também chamo atenção para os problemas provocados pelas intenções de produzir traduções como "textos transparentes" gerando o que o tradutor e teórico Lawrence Venuti (2004, p. 1) chama de "tradutor invisível", ou seja, aquele capaz de produzir traduções tão satisfatórias que é como se o leitor olhasse diretamente para o texto de saída, como se o tradutor não existisse ou não estivesse entre a versão original e a tradução. Navegar por duas esferas de saberes, a da cultura da língua de chegada e a da cultura da língua de saída, também carrega consigo certa manipulação que vai trabalhar em favor dos propósitos já citados.

Dentro de uma categoria de conhecimento onde se lida com tanto poder quanto a tradução, é interessante pensar em casos específicos que têm um grande impacto nas sociedades onde surgem e como essas mensagens e representações são transportadas para outras culturas. Assim, as perguntas que guiam este ensaio são: como agem relações de poder que estão em jogo nos movimentos a que se submete um texto quando traduzido, especialmente quando a publicação em questão é tão significativa para a cultura que o gerou, como é o caso da obra da escritora Carolina Maria de Jesus? E quais são os impactos dessa tradução tanto na cultura de saída quanto na de chegada? E, finalmente, como autora e personagens são (re)construídos pelo processo de tradução?

Como nem original nem traduções existem num vazio, cabe aqui uma breve introdução contextual para a compreensão dos argumentos que defendo mais adiante. A escritora Carolina Maria de Jesus foi uma mulher negra que viveu entre os anos de 1914 a 1977 em um Brasil recémliberto da escravidão, abolida em 1888. É importante salientar que o governo brasileiro não ofereceu nenhuma medida de amparo aos homens e mulheres negros que foram escravizados em solo nacional. Pelo contrário, eles foram vistos por muitos anos como o motivo do atraso da sociedade brasileira e sofreram com um longo processo de opressão social, cultural e física que atuou de formas variadas no que Abdias do Nascimento chamou de "genocídio" na obra O genocídio do negro brasileiro, publicada em 1978. Entre os episódios que cita estão o processo de embranquecimento através do incentivo da imigração estrangeira, a perseguição à cultura negra e sua criminalização e a falta de políticas sociais que buscassem integrar de maneira igualitária as raças no Brasil.

Na época em que viveu Carolina Maria de Jesus, a situação dos negros no país era ainda muito precária. Ex-escravizados e seus descendentes procuravam uma maneira de sobreviver se mudando para as grandes cidades em busca de trabalho e, sem condições financeiras para pagar por moradia, acabavam por viver nas periferias ou nas favelas, como aconteceu com Carolina, que foi de Minas Gerais à favela do Canindé na cidade de São Paulo. Em seus diários, a autora relata sua vida cotidiana. Os diários são únicos na forma como apresentam a existência daqueles marginalizados com base em raça e classe, principalmente, e de como lidam com a espacialização das cidades brasileiras. No entanto, para um público leitor de classe média e média alta de maioria branca, o que chamava a atenção era a vida de uma catadora de papel negra e favelada, mãe de três filhos e letrada. ${ }^{1}$ Carolina Maria de Jesus virou curiosidade

\footnotetext{
${ }^{1}$ De acordo com os dados apresentados por Ferraro (2002), 39.7\% da população brasileira com 10 anos ou mais era analfabeta em 1960.
} 
nacional e, como explica o historiador americano Robert M. Levine, que estudou a vida e a obra da autora, no posfácio da edição de 2003 de Child of the dark, ela e seus diários se tornaram um símbolo temporário da meritocracia (Jesus, 1999, p. 189). Esse conceito refere-se à ideia de que sucesso é resultado de trabalho árduo, minimizando o impacto que as condições socioeconômicas da realidade brasileira têm sobre a vida dos cidadãos.

Antes de chegarmos a The unedited diairies of Carolina Maria de Jesus, vale a pena explicar o contexto de criação do predecessor, Child of the dark, a tradução do famoso Quarto de despejo (1960) publicada originalmente em 1962. O responsável pela tradução foi o jornalista da revista americana Time and Life, David St. Clair (1931-1991). ${ }^{2}$ St. Clair acaba virando um dos personagens de Casa de alvenaria (1962) e é citado por Carolina diversas vezes, pois conduziu uma série de reportagens sobre a autora (Ferreira, 2009, p. 1). O historiador americano Robert M. Levine e o historiador brasileiro José Carlos Sebe Bom Meihy, já mencionados aqui, dão as bases para se entender as implicações políticas da tradução da primeira obra de Carolina Maria de Jesus no prefácio e posfácio de Meu estranho diário e nas mesmas secções de The unedited diaries of Carolina Maria de Jesus.

A década de 1960 foi marcada pelas tenções políticas entre o bloco socialista e a defesa do sistema capitalista pelos Estados Unidos da América em conjunto com outros países e, especialmente, pelo fim da Revolução Cubana com a vitória do movimento comunista, o que sinalizava que os países da América Latina, como o Brasil, que tinha significativos movimentos esquerdistas, poderiam seguir o mesmo rumo. Nesse contexto, enfatizar a situação de países mais pobres que se viam no meio da disputa e principalmente daqueles na América Latina que tendiam perigosamente, segundo a visão americana, para a esquerda, era interessante. A ênfase na pobreza dessas sociedades era uma forma de mostrar o fracasso de países que se aproximavam mais das ideologias marxistas e, assim, justificar qualquer forma de intervenção.

Carolina Maria de Jesus deu atenção à situação política no Brasil da época em seu diário. Enquanto no Brasil a projeção internacional de Carolina de Jesus era vista com receio por conta da imagem de pobreza e negritude que carregava consigo, os Estados Unidos e a Europa, que passavam por um complicado contexto geopolítico, se viram chocados com a dimensão dos problemas sociais e econômicos no Brasil (Levine e Meihy, 1995, p. 68). Como explica Elzira Divina Perpétua em A vida escrita de Carolina Maria de Jesus:

As estratégias de condução da leitura das traduções de Quarto de Despejo levam a uma imagem que, desconsiderando quase completamente a narrativa de Carolina como manifestação individual, erige sua autora à condição de uma síntese da miséria de um país, às vezes de um continente (Perpétua, 2014, p. 133).

Um dos maiores exemplos da importância dos diários no exterior foi a produção de um documentário sobre a vida de Carolina de Jesus ainda no início da década de 60 na Alemanha Ocidental (1949-1990), a parte capitalista (Jesus, 1999, p. 212). Era impossível ver o contexto exposto por Carolina de Jesus fora da complicada dimensão política global.

Levine e Meihy sublinham a importância política dos diários, que venderam mais de um milhão de cópias desde 1960 (Jesus, 1999, p. 1), no Brasil e, principalmente, nos Estados Unidos. Os autores afirmam que: "A escrita de Carolina nunca foi considerada literatura; sua escrita foi aclamada por aquilo que revelava sobre a natureza da pobreza no Terceiro Mundo e sua autora celebrada por dar voz ao que os estrangeiros viram como um eloquente grito por socorro." (Levine e Meihy, 1995, p. 68, tradução nossa). ${ }^{3}$

No contexto que sublinho aqui, a autora contribui com passagens relevantes e que poderiam ser entendidas de maneiras diferentes pela polarização política em questão, como evidencia a

\footnotetext{
2 Mais informações sobre a visita de St. Clair ao Brasil e projetos paralelos podem ser encontradas em sua página: http://karengresham.com/intuitive-medium-about/david-st-clair/

${ }^{3}$ Em outra passagem significativa sobre a recepção dos diários de Carolina Maria de Jesus nos Estados Unidos, Levine e Meihy afirmam que: "Progressistas, preocupados com o legado do subdesenvolvimento no Terceiro Mundo, viram seu diário como um olhar sobre o que Oscar Wilde mais tarde chamou de "cultura da pobreza". Críticos elogiaram a importância de Child of the dark chamando-o "imensamente perturbador" e adicionando suas análises sobre as causas das condições de Carolina de Jesus descrita para o debate sobre as formas de combater a pobreza no hemisfério de acordo com o espírito da Aliança para o Progresso da administração de Kennedy" (Levine, Meihy, 1995, p. 69, tradução nossa).
} 
seguinte entrada de 16 de agosto: "Antigamente era os operarios que queria o comunismo. Agora, são os patrões. O custo de vida faz o operario perder a simpatia pela democracia" (Jesus, 2007, p. 112). Fica claro que Jesus não apenas entendia o contexto político como discutia-o com aqueles que encontrava pela cidade. Na passagem acima, comunismo e democracia são opostos e, a seguir, a revolução é entendida como possível consequência para a precária economia nacional: "Se o custo de vida continuar subindo até 1960 vamos ter revolução!" (Jesus, 2007, p. 131).

Ressaltando a pobreza, os atos de publicação e tradução da obra de Carolina Maria de Jesus acabam se tornando uma ferramenta que atesta a necessidade da América Latina de receber mais "capitalismo". O governo militar que se instala no Brasil apenas quatro anos depois da publicação de Quarto de despejo e apenas dois anos depois do lançamento de Child of the dark como uma maneira de "proteger" o país do comunismo são evidências suficientes do significado que essa tradução poderia ter para os países envolvidos diretamente nesses conflitos (Motta, 2002, p. 4). Vale lembrar que até hoje a pobreza ainda é utilizada como sinal de fracasso e ferramenta contra os países que continuam a funcionar sob uma economia comunista, como é o caso de Cuba, Rússia, Angola, entre vários outros ${ }^{4}$ além de ser usada para justificar intervenções políticas radicais, como recentemente aconteceu no Brasil. Bassnet e Trivedi (2002, p. 5-6) falam das implicações da tradução de textos para línguas europeias e do perigo de que ela possa contribuir para o processo de colonização, bem como da existência de qualquer tradução numa esfera que está sempre permeada por fatores culturais, políticos e históricos. No caso das traduções da obra de Carolina Maria de Jesus, como fica perceptível pelo contexto histórico, é bem provável que seu uso tenha ido exatamente de encontro à manutenção de sistemas de poderes.

O êxito dos diários em toda a América e majoritariamente nos Estados Unidos também é significativo para que se entenda a importância de suas traduções. Levine e Meihy (Jesus, 1996, p. 27) escrevem sobre a conhecida notoriedade de Carolina Maria de Jesus na sociedade americana e, ao contrário do que acontece no Brasil, a solidificação de seu sucesso em meios acadêmicos, notavelmente nas áreas de antropologia e sociologia em que é transformada em caso de estudo, enquanto renegada pela crítica literária.

Outra dimensão histórica que não pode ser esquecida é aquela da luta pelos direitos civis nos Estados Unidos, que tem seu auge na década de 60 bem como o movimento de independência de diversos países africanos. No entanto, o Brasil ainda tentava vender a imagem de paraíso racial difundida nos anos 30 por autores como Gilberto Freyre, defendida e popularizada pelo governo militar ditatorial a partir de 1964 tendo como contraponto a realidade americana em que precisavam lidar com a violência gerada pela segregação racial (Guimarães, 2001, p. 61-62). Os diários de Carolina Maria de Jesus servirão, então, para mostrar como essa caracterização da sociedade brasileira como uma comunidade sem racismo não passa de ficção e que o preconceito baseado na cor da pele sempre esteve ativo no país, ainda que de maneiras diferentes daquelas praticadas nos países anglófonos.

\section{Editando Carolina Maria de Jesus}

Como explica Elzira Divina Perpétua (2014, p. 129) e também Ana Paula Ferreira (2009, p. 2-3), Quarto de despejo é apresentado nos prefácios do editor, Audálio Dantas, e de seu primeiro tradutor como um "fato inusitado, quase como um milagre" (Perpétua, 2014, p. 130) que só é possível através do "descobrimento" de Dantas. A sugestão é de que, não fosse pela intervenção do homem branco e educado, a autora Carolina Maria de Jesus jamais seria publicada. A estrutura das edições e traduções refletem e reforçam essa crença.

Quarto de despejo, como já se sabe, foi editado pelo jornalista Audálio Dantas que, apesar de dizer o contrário, alterou consideravelmente a linguagem da autora, corrigindo alguns desvios na estrutura e na ortografia e moldando os diários ao público que poderia pagar pela publicação naquela época. Por meio da comparação entre Quarto de despejo e Meu estranho diário, cuja proposta é

\footnotetext{
${ }^{4}$ Um exemplo pode ser encontrado em "Poverty, Hunger and Other Evils of Communism" de Stephen Chapman. Disponível em: http://articles.chicagotribune.com/1990-01-25/news/9001070410_1_soviet-miners-soviet-people-soviet-ambassador
} 
justamente a de publicar os diários sem nenhuma edição, é fácil ver que a parte mais significativa da edição produzida por Dantas, no entanto, foi o corte de muitas partes dos textos originais, notavelmente aquelas em que de Jesus fazia críticas mais enfáticas a pessoas públicas ou reproduzia discursos racistas famosos na época, como os ataques aos nordestinos, provavelmente porque isso dificultaria a publicação da obra. Esse processo de edição é bastante problemático porque produz uma personagem que foi transformada para os receptores do mercado editorial da década de 60 mascarando a personagem que realmente estava presente nos diários. A primeira tradução dos diários é produzida praticamente sob um processo de "tradução intralingual" como explicou Roman Jakobson (1987, p. 429), ou seja, uma espécie de adaptação na própria língua de saída que daria os frutos esperados pelos editores.

É interessante notar a partir desse contexto as escolhas de David St. Clair para a tradução dos diários. Em qualquer edição de livro, é comum corrigir os erros ortográficos dos autores. No caso de Carolina Maria de Jesus, Audálio fez o mesmo, mas preservou alguns desses desvios ortográficos porque contribui para a ideia de uma autora semianalfabeta, um julgamento que ainda sobrevive mesmo depois de ela ter escrito mais de quatro mil páginas (Jesus, 1997, p. 7), embasado no fato de que de Jesus somente havia frequentado dois anos de escola regular. A edição de Dantas corrobora para os limites da produção de conhecimento impostos àquelas que se identificam como mulher negra, pobre, mãe solteira e residente de uma favela (Santos, 2014, p. 6).

Um exemplo das alterações às quais me remeto são vistas nas seguintes passagens e se mantém ao longo dos escritos originais transcritos em Meu estranho diário:

Fiquei contente Achei um saco de fuba no lixo e trouxe para dar ao porco. Eu ja estou tao habituada com as latas de lixo que não sei passar por elas sem ver o que ha dentro. Hoje eu não fui catar papel porquê sei que não vou encontrar nada Tem um velho que circula na minha frente. Hontem eu li aque fabula da rã e a vaca Tenho a impressão que sou rã Que queria crescer ate ficar do tamanho da vaca - Eu desejei varios empregos (Jesus, 1996, p. 38).

Em Quarto de despejo podemos ver como os diários foram alterados por Dantas. Ele usou reticências para indicar as partes suprimidas do texto original e fez alterações significativas para a estrutura e especialmente para o significado:

1 de novembro ... Achei um saco de fubá no lixo e trouxe para dar ao porco. Eu já estou tão habituada com as latas de lixo, que não sei passar por elas sem ver o que há dentro. Hoje eu vou catar papel porque sei que não vou encontrar nada. Tem um velho que circula na minha frente. Ontem eu li aquela fabula da rã e a vaca. Tenho a impressão que sou rã. Queria crescer até ficar do tamanho da vaca (Jesus, 2007, p. 125, grifo nosso).

As duas versões mostram alterações bem controladas e intencionais. Além de modificações ortográficas como "aque" por "aquela," que facilitam a leitura, Dantas decide não corrigir a acentuação em "fabula." Além disso, o sentido das duas últimas frases é modificado com a supressão da conjunção "que", o que tira a ambiguidade da frase onde não temos certeza se Carolina fala da rã que queria crescer ou de si mesma. Na versão de Dantas não é a rã que queria crescer e ficar do tamanho da vaca, mas indubitavelmente a própria personagem.

\section{Traduzindo Carolina}

A questão central para a tradução se concentra em torno da decisão de tentar reproduzir ou não os "desvios" da norma culta do português em que incorre de Jesus. E, se a opção for a da reprodução, como fazê-lo já que o que se constitui "erro ortográfico" em português não é necessariamente um erro ortográfico em inglês. Além, é claro, de considerar o impacto que essas modificações têm para a construção de uma representação da autora no imaginário de seus leitores.

Uma pausa é necessária aqui para reavaliar o propósito deste ensaio. Críticos como Venuti já apontaram para diversos questionamentos relacionados à invisibilidade do tradutor e todos os problemas advindos daí. Assim, esse ensaio não pretende colaborar para essa invisibilidade e muito menos para a demonização das traduções e, especialmente, dos tradutores. A maneira como as traduções da obra de Carolina Maria de Jesus são entendidas aqui decorrem de minha 
posição enquanto crítica literária em pensar problemas relacionados à tradução sem deixar de reconhecer todos os benefícios que essa traz consigo, especialmente para a produção de conhecimento em torno da literatura. Casos como os das traduções de Carolina Maria de Jesus servem para a reflexão e para que novas estratégias sejam desenvolvidas.

Em se tratando dos três tradutores de quem falarei aqui, vale também ressaltar a contribuição que esses deram para a popularização de uma escritora tão importante dentro e fora do Brasil. As traduções trouxeram grande prestígio para Carolina no estrangeiro e isso fez com que a autora fosse "redescoberta" mais tarde pela academia brasileira por meio do projeto da década de 1990 conduzido por Levine e Meihy.

\section{A tradução de David St. Clair}

Em 1962 é publicada nos Estados Unidos a tradução de David St. Clair: Child of the dark. Essa primeira tradução traz um prefácio do tradutor que merece ser analisado com cautela. Nele, o tradutor faz uma longa e tocante descrição da vida da autora de maneira a criar de antemão uma personagem antes mesmo da leitura inicial dos diários. Ele menciona as estratégias de tradução apenas no seguinte parágrafo:

As palavras de Carolina são as palavras da rua. Seu português não é a fluida linguagem clássica falada pelas classes altas, mas a fala curta, urgente e agitada do pobre. Ela não foi ensinada na escola a fazer parágrafos e ser consistente com os tempos verbais. Nada disso foi alterado na tradução, já que fazê-lo seria alterar a própria mulher. Ela escreve de forma direta, brusca e sem artifícios. Ela registrou o que viu de tal forma que faz o leitor senti-lo. Um grande feito (Jesus, 2003, p. 16, tradução nossa).

Como fica perceptível, trata-se de um comentário contendo mais sua opinião sobre a escrita de Carolina Maria de Jesus do que de sua tradução propriamente dita. No entanto, ele nos deixa saber que não produziu alterações estruturais no trabalho (o que seria impossível considerandose a própria essência da tradução). Ressalto também que os estudos de tradução ainda não haviam se popularizado como acontece hoje e que era completamente normal para um tradutor se expressar dessa forma sobre uma obra e um autor, ou até mesmo não produzir explicações maiores sobre sua abordagem de tradução. Como exemplo do trabalho de St. Clair, transcrevo sua tradução do trecho citado anteriormente em português:

November 1 I found a sack of corn flour in the garbage and brought it home for the pig. I am so used to garbage can that I don't know how to pass one without having to see what is inside. Today I'm going out to look for paper but I know I'm not going to find anything. There is an old man who is in my territory. Yesterday I read that fable about the frog and the cow. I feel that I am a frog. I want to swell up until I am the same size as the cow (Jesus, 2003, p. 133).

St. Clair tenta reproduzir a estrutura sem reproduzir os erros ortográficos que encontramos em Quarto de despejo somando-se a isso o fato de não ter incluído as reticências que Dantas usou para marcar as supressões do original. Apesar da estrutura de uma obra ser sempre significativa, a decisão de não reproduzir os desvios ortográficos pode ser interpretada de duas maneiras: ou como um sinal de violência que aparece na rejeição da equivalência ou como forma de mostrar sua impossibilidade. É relevante dizer que os desvios ortográficos geralmente seriam corrigidos numa edição de qualquer outro livro e que, nesse caso, o conteúdo da obra é mais relevante do que tentar preservar os erros ortográficos de Carolina Maria de Jesus.

A manutenção da estrutura de erros ortográficos como os que aparecem na obra da autora somente são importantes se foram intencionais e, no caso de Carolina Maria de Jesus, sabemos que não foram. Manter esses desvios ou tentar reproduzi-los numa outra língua, recriando-os, já que seriam impossíveis de serem repetidos em inglês tal como são em português, é adotar uma forma de representação da autora que é fruto da edição e da tradução. Acredito que a estratégia de St. Clair tenha sido satisfatória e que, por mais que gere discussões, elas são necessárias e importantes para que se pense o que se pretende ou qual é o papel da tradução e suas táticas. 
Outro problema que resvala consideravelmente em aspectos de representatividade é a tradução do vocabulário caroliniano. De Jesus escolhia conscientemente palavras mais sofisticadas que contrastavam com a estrutura direta e os desvios ortográficos que comete ocasionalmente. $\mathrm{O}$ uso de maneirismos vocabulares solidificava a ideia que a autora tinha de autoria e literatura, ou seja, para ser reconhecida enquanto escritora, era necessário usar palavras incomuns ao vocabulário urbano. Por vezes, St. Clair decidiu não respeitar essa decisão utilizando palavras mais simples em inglês para traduzir essas expressões. Como vemos na seguinte tabela:

\begin{tabular}{|c|c|}
\hline Original & Tradução \\
\hline “Hoje a Leila está embriagada.” (Jesus, 2007, p. 73) & “Today Leila is drunk." (Jesus, 2003, p. 65) \\
\hline $\begin{array}{l}\text { “O único que está alcoolizado é o Valdemar” } \\
\text { (Jesus, 2007, p. 74). }\end{array}$ & $\begin{array}{l}\text { "The only one whos really drunk is Valdemar" } \\
\text { (Jesus, 2003, p. 66). }\end{array}$ \\
\hline $\begin{array}{l}\text { “O pernambucano saiu correndo, gritando e } \\
\text { bradando" (Jesus, 2007, p. 76). }\end{array}$ & $\begin{array}{l}\text { "The Pernambucano ran out snorting and } \\
\text { shouting" (Jesus, 2003, p. 68). }\end{array}$ \\
\hline $\begin{array}{l}\text { "A minha simpatia pela dona Chiquinha } \\
\text { arrefeceu" (Jesus, 2007, p. 79). }\end{array}$ & $\begin{array}{l}\text { "My friendship for Dona Chiquinha cooled off" } \\
\text { (Jesus, 2003, p. 71). }\end{array}$ \\
\hline $\begin{array}{l}\text { "Se o Frei visse os seus filhos comendo generos } \\
\text { deteriorados, comidos pelos corvos e ratos, havia } \\
\text { de revoltar-se, porque a revolta surge das agruras" } \\
\text { (Jesus, 2007, p. 86). }\end{array}$ & $\begin{array}{l}\text { "If the Brother saw his children eating rotten } \\
\text { food already attacked by vultures and rats, he } \\
\text { would stop talking about resignation and rebel, } \\
\text { because rebellion comes from bitterness" (Jesus, } \\
2003 \text {, p. } 77 \text { ). }\end{array}$ \\
\hline “-Aquele negro sujo me bateu” (Jesus, 2007, p. 98). & “That dirty nigger hit me!” (Jesus, 2003, p. 89). \\
\hline $\begin{array}{l}\text { "Eu suicidando-me é por deficiência de } \\
\text { alimentação no estomago" (Jesus, 2007, p. 100). }\end{array}$ & $\begin{array}{l}\text { "But I am killing myself now, by lack of food in } \\
\text { the stomach" (Jesus, 2003, p. 92). }\end{array}$ \\
\hline “Eu não compareci” (Jesus, 2007, p. 102). & "I didn't go" (Jesus, 2003, p. 93). \\
\hline $\begin{array}{l}\text { "E um dia, a dona Maria ao chegar em casa, } \\
\text { encontrou o Policarpo e a prima, na *copola" } \\
\text { (Jesus, 2007, p. 107) (*cópula). }\end{array}$ & $\begin{array}{l}\text { "One day when Dona Maria returned to the shack } \\
\text { she found Policarpo and the cousin screwing" } \\
\text { (Jesus, 2003, p. 98). }\end{array}$ \\
\hline $\begin{array}{l}\text { "Eu só tenho dó das crianças que ouvem os } \\
\text { improperios" (Jesus, 2007, p. 109). }\end{array}$ & $\begin{array}{l}\text { "I only feel sorry for the children who have to hear } \\
\text { such language" (Jesus, 2003, p. 100). }\end{array}$ \\
\hline $\begin{array}{l}\text { "Mas estava aflita por causa dos filhos que haviam } \\
\text { ficado sosinho" (Jesus, 2007, p. 115). }\end{array}$ & $\begin{array}{l}\text { "But I was worried about the children that I had } \\
\text { left alone" (Jesus, 2003, p. 105). }\end{array}$ \\
\hline
\end{tabular}

Essas decisões refletem e contribuem para a representação popular de Carolina Maria de Jesus como semianalfabeta através da simplificação de seu vocabulário. Tradutores atentos provavelmente escolheriam traduzir, por exemplo, "embriagado" e "alcoolizado" como "inebriated" or "intoxicated" também seria fácil pensar em "Eu não compareci" como "I did not attend it". Para o contexto americano em que essa publicação foi lançada, quando o movimento pelos direitos civis nos Estados Unidos estava em seu auge, a decisão de utilizar a palavra "nigger" também é bastante significativa, uma vez que "preto" e "negro" como os próprios usos que Carolina faz dos dois termos em seus diários demonstra, não é equivalente a "nigger" e não têm o peso da conotação ofensiva que carregam nos Estados Unidos.

\section{A tradução de Nancy P. S. Naro e Cristina Mehrtens}

Já a tradução de Meu estranho diário foi publicada em 1999 sob o título de The unedited diaries of Carolina Maria de Jesus. As duas obras foram o resultado de um projeto dos organizadores José 
Carlos Sebe Bom Meihy e Robert M. Levine. O projeto visava "redescobrir" a obra de Carolina Maria de Jesus que havia sido praticamente esquecida no Brasil por aproximadamente trinta anos. Os historiadores buscaram pelos filhos da autora e conseguiram de Vera Eunice de Jesus Lima, a filha de Carolina Maria de Jesus, os originais que decidiram publicar em Meu estranho diário. A intenção, portanto, era de que a obra fosse comparada a Quarto de despejo para dar uma visão mais honesta do que eram os diários, bem como fazer visíveis as edições de Audálio Dantas, acabando, por exemplo, com as dúvidas de que Dantas havia modificado os diários a ponto de ser considerado o autor principal, o que o próprio jornalista já havia negado (Jesus, 2007, p. 6-7). Os editores de The unedited diaries foram os primeiros a apontar um processo de construção de uma personagem através das edições dos livros de Carolina: "A edição por deleção extensiva de Dantas resultou numa imagem dimensional da autora e de sua visão de mundo" (Jesus, 1999, p. 3, tradução nossa). A publicação centra-se nas partes que foram suprimidas por Dantas com alguns poucos trechos que se repetem em Quarto de despejo e Meu estranho diário.

Sobre a tradução é interessante que uma obra ao mesmo tempo tão importante e tão desafiadora não possua um prefácio ou comentário das tradutoras, como fez David St. Clair. No entanto, os editores afirmam que o livro é "uma tradução fiel das entradas do diário encontrado entre os materiais entregues a nós por Vera Eunice de Jesus Lima" (Jesus, 1999, p. 3, tradução nossa). A falta de um comentário das tradutoras pode ter sido uma decisão da editora, mas em se tratando de uma tradução tão complexa acho que os responsáveis poderiam ser persuadidos a incluir pelo menos algumas notas. Existe somente um glossário de palavras e nomes que não foram traduzidos. Entrei em contato com a Profa. Mehrtens que mencionou brevemente por correspondência eletrônica a dificuldade de traduzir os diários. Ela explica que usaram mais de uma versão dos originais, o que dificultou ainda mais o trabalho. Ela não menciona Meu estranho diário, mas o colofão do livro traz a informação de que se trata de uma tradução de seleções de Meu estranho diário em conjunção com um original de 1966. Um segundo aspecto notável é como a escolha das entradas foi feita. Por exemplo, há supressão de algumas datas, como os dias 22 e 23 de novembro que aparecem em Meu estranho diário, mas não na tradução e sem nenhuma justificativa.

À luz dos recentes estudos da tradução que se desenvolviam na década de 90, Naro e Mehrtens são mais cuidadosas com a tradução das palavras sofisticadas usadas por Carolina. No entanto, alguns problemas ainda são detectados, como vemos na seguinte tabela:

\begin{tabular}{|l|l|}
\hline \multicolumn{1}{|c|}{ Original } & \multicolumn{1}{c|}{ Tradução } \\
\hline $\begin{array}{l}\text { "Eu notei anormalidade porque a policia esta nas } \\
\text { ruas" (Jesus, 1996, p. 33). }\end{array}$ & $\begin{array}{l}\text { "I sensed that something was up since there are } \\
\text { police in the streets" (Jesus, 1999, p. 21). }\end{array}$ \\
\hline $\begin{array}{l}\text { "Na rua pedro viçente um senhor que estava } \\
\text { retirando seus apetrechos de trabalho deu-me } \\
\text { umas latas" (Jesus, 1996, p. 35). }\end{array}$ & $\begin{array}{l}\text { "On Pedro Vicente street a man who was } \\
\text { throwing out his garbage gave me some cans" } \\
\text { (Jesus, 1999, p. 22). }\end{array}$ \\
\hline $\begin{array}{l}\text { "Hoje trabalha demasiadamente e são infaustos" } \\
\text { (Jesus, 1996, p. 36). }\end{array}$ & $\begin{array}{l}\text { "Today they work too much and are miserable" } \\
\text { (Jesus, 1999, p. 23). }\end{array}$ \\
\hline $\begin{array}{l}\text { "Vi as mulheres da favela agitadas e falando" } \\
\text { (Jesus, 1996, p. 36). }\end{array}$ & $\begin{array}{l}\text { "I noticed that the shantytown women were } \\
\text { upset and talking" (Jesus, 1999, p. 24). }\end{array}$ \\
\hline $\begin{array}{l}\text { "O povo esta dizendo que o dr. Adhemar elevou- } \\
\text { se a passagem para vingar do povo porque lhe } \\
\text { preteriam nas urnas" (Jesus, 1996, p. 37). }\end{array}$ & $\begin{array}{l}\text { "The people are saying that Dr. Adhemar raised } \\
\text { fares to get back at them for not voting for him" } \\
\text { (Jesus, 1999, p. 24). }\end{array}$ \\
\hline
\end{tabular}

Cabe perguntar, portanto, até que ponto a maior atenção e uma tradução mais literal permitem o uso de algumas liberdades na tradução sem impactar a representação que The unedited diaries traz de Carolina. Porque a autora corporifica intersecções de gênero, raça, classe e transnacionalidade, no caso das duas traduções, meu argumento é de que qualquer 
representação que contribua para a reificação de um estereótipo de mulher negra e pobre é prejudicial para a imagem produzida pela tradução. O impacto é ainda maior quando consideramos que essas construções se dão por meio da língua, o instrumento que Carolina manejava para reclamar tanto sua identidade enquanto autora, quanto para alcançar ascensão social e mobilidade espacial. Minha preocupação com a representação produzida pela estrutura linguística tanto em português quanto em inglês é justificada pela facilidade que essas representações estruturais têm de passar despercebidas por leitores que desconhecem as especificidades dos processos de edição, tradução e publicação. Ponderando que as traduções são feitas para um público estrangeiro em determinado contexto histórico e político numa economia capitalista neoliberal em que sistemas de poder afetam territórios específicos diferentemente, a magnitude dessas representações não pode ser negligenciada.

Quanto à tradução da estrutura, se faz necessário que analisemos exemplos. Cito o início do relato do dia primeiro de novembro, o mesmo cuja versão original analisei anteriormente:

I was pleased I found a sack of cornmeal in the garbage and brought it home for the pig. I am so used to garbage cans that I can't pass them without fishing about inside. Today I didn't go after paper since I know I won't find any. An old man gets there before me. Yesterday I read the fable of the frog and the cow I have the impression that I am the frog That he wanted to grow to the size of the cow - I wanted many jobs (Jesus, 1999, p. 25).

A opção de tradução do verbo "ver o que há dentro" foi por "fishing about," que implica mexer manualmente, fuçar, enquanto St. Clair decide por uma versão mais literal: "to see what is inside," o que faz mais sentido já que não está claro se a personagem realmente manipula ou apenas olha as latas de lixo. A tradução de Naro e Mehrtens, assim, é um pouco mais tendenciosa ao conectar a personagem diretamente ao lixo.

Há também o complicado processo de tradução de uma obra com desvios ortográficos que estão lá propositalmente, segundo o objetivo de publicar os diários sem ed ição. Como transportar erros de ortografia para uma outra língua? Qualquer reprodução desses erros seria uma criação, pois eles não existem na língua de origem. Um exemplo é necessário para que se entenda como isso se torna uma dificuldade. Cito abaixo o original seguido da tradução do relato referente ao dia 21 de novembro.

Eu fui no deposito de ferro vender um pouco de estopa. ganhei 36 - Entrei na padaria guine e tomei 1 copo de leite Cheguei em casa comprei 1 litro de leite para os filhos. Mandei o João comprar 1 litro de querosene (Jesus, 1996, p. 90).

I went to the scrap metal depot to sell a little oakum. i got 36 cruzeiros - I went to the guine bakery and had 1 glass of milk I got home i bought 1 liter of milk for the children. I sent João for 1 liter of kerosene (Jesus, 1999, p. 62).

Meu primeiro estranhamento com a tradução dessa passagem foi o uso do "I" (eu) em inglês que só pode ser grafado em letra maiúscula. $\mathrm{O}$ uso do " $\mathrm{i}$ " dessa forma, em letra minúscula, configuraria um erro em inglês, mas não em português. Se prestarmos a devida atenção, é perceptível que as tradutoras entendiam que se tratava de uma nova frase (o que é questionável) e buscavam reproduzir a maneira como Carolina Maria de Jesus iniciava as orações sem o uso da maiúscula que marca o começo das sentenças em português. No entanto, no inglês, o contraponto com as frases em que "I" aparece grafado da maneira correta faz com que esse desvio pareça grosseiro aos olhos dos leitores de língua inglesa que atribuem o erro à autora e não a uma decisão das tradutoras.

A segunda pergunta que é crucial para o entendimento dessa postura passa a ser a seguinte: por que transportar esses desvios específicos para o inglês e qual o efeito dessa tradução? Já que nem todos os erros são traduzidos, imagina-se que as tradutoras buscavam ao menos uma equivalência parcial com o original. Hoje já entendemos que a busca de equivalência é, como coloca Ben Conisbee Baer (2014, p. 239, tradução nossa), ao tratar da tradução pós-colonial, uma fantasia: "o desejo inescapável e aposta da tradução - sua fantasia - é por absoluta transparência de sentido, a produção impossível de equivalência sem resíduo". Assim, elas poderiam ter escolhido não transportar nenhum desses desvios e desistir da utópica 
equivalência sem maiores problemas do ponto de vista da crítica pós-colonial, mas talvez não da perspectiva editorial e do público leitor em outra cultura que têm certas expectativas em torno do que (e de quem) vão ler. Ou seja, uma favelada negra e mãe solteira que cata papel no lixo para sobreviver e é semianalfabeta não poderia escrever em uma língua própria do que é esperado nos meios literários. Há que se transportar erros ortográficos.

Como explica Lenita Esteves em Atos de tradução: "a tradução pode ser uma poderosa arma de intervenção política, seja para dominar ou para contra-atacar o poder do dominador" (Esteves, 2014, p. 273). Não excluo a possibilidade de que as traduções das obras de Carolina Maria de Jesus, ao transporem os erros ortográficos ou estruturais, possam, sim, ser entendidas como um ato de subversão da forma literária e que trabalhem para a visibilidade de outras classes sociais e outras possibilidades linguísticas. No entanto, o ato subversivo geralmente pressupõe uma atitude consciente e não recai sobre a representação do autor. Como expliquei anteriormente, os desvios na obra de Carolina Maria de Jesus não foram intencionais. Tanto é assim que foram parcialmente editados em Quarto de despejo e suprimidos em Child of the dark. O que me faz entender as decisões das tradutoras de Meu estranho diário como trabalhando em favor da construção de um outro que se pode dominar.

\section{Conclusão}

Ao considerar as posições de Tymoczko sobre os três estágios que governam as traduções, Lenita Esteves aponta o seguinte:

[...] as traduções e os tradutores são consequência e reflexo de uma época, de uma ideologia e de muitas outras restrições. Em vez de considerar ética da tradução em termos do que é "bom" ou "ruim", ou mesmo em termos de qual estratégia é mais aceitável ou respeitosa em relação ao texto fonte, é mais produtivo pensar nas traduções como objetos culturais que são moldados e têm papel moldador numa certa cultura (Esteves, 2014, p. 284).

Enquanto "objeto cultural" é de valor inestimável a obra de Carolina Maria de Jesus tanto para as culturas que recebem as traduções quanto para a cultura brasileira. Nessas duas esferas, seus diários vêm sofrendo desde seu "descobrimento" grande manipulação, primeiramente pelas mãos de Audálio Dantas, em seguida por meio dos diversos tradutores que os levaram a outros vários idiomas. Como explica Esteves, traduções tão complexas e envoltas em implicações que vão além das literárias, as estratégias de tradução da obra de Carolina Maria de Jesus precisam ser pensadas em torno de questões éticas e políticas, de como a tradução está ou não colaborando para a manutenção de estruturas de poder que agem sobre aqueles na condição da autora reforçando representações que trabalham em favor de dinâmicas neocoloniais.

Ao discutir as edições e traduções das obras de Carolina Maria de Jesus, esbarra-se nas questões sobre a possibilidade de sujeitos subalternizados produzirem discursos que não sejam imediatamente colonizados e empregados na manutenção de discursos hegemônicos (Spivak, 1994, p. 184). As teorias pós-coloniais da tradução não são muito otimistas ao considerarem a viabilidade das traduções servirem projetos de descolonização, preponderantemente por conta do contexto em que são produzidas. O pessimismo aumenta quando casos como das traduções das publicações de Carolina Maria de Jesus examinados nesse artigo são trazidos à tona ressaltando a pergunta: Quais medidas seriam necessárias para que os diários de Carolina Maria de Jesus fossem lidos, tanto no Brasil como no exterior, como a autora intencionava? Parece-me óbvio que o problema está realmente na invisibilidade que Venutti discute e que eu vejo nas ciências sociais como a questão da imparcialidade. Em outras palavras, tal como em artefatos culturais e no fazer científico, os produtores de publicações e traduções não devem escapar ao escrutínio da crítica, não deveriam ser tratados como invisíveis justamente porque são sujeitos políticos envolvidos em contextos socioeconômicos e históricos. Usando a mesma lógica, a posicionalidade daqueles que recebem essas produções e daqueles que as analisam, bem como de seus impactos, precisam de considerações cuidadosas para que desenvolvamos as ferramentas necessárias para uma leitura não somente eficiente, mas ética. 


\section{Referências}

BAER, Ben Conisbee (2014). What is Special about Postcolonial Translation? In: BERMANN, Sandra; PORTER, Catherine (Org.). A Companion to Translation Studies. $1^{\text {st }}$ ed. Chichester, West Sussex: Wiley Blackwell.

BASSNET, Susan; TRIVEDI, Harish (2002). Introduction: of colonies, cannibals and vernaculars. In: BASSNET, Susan; TRIVEDI, Harish (Org.). Post-colonial Translation: Theory and Practice. New York: Routledge.

ESTEVES, Lenita Maria Rimoli (2014). Atos de tradução: Éticas, intervenções, mediações. São Paulo: Humanitas.

FERRARO, Alceu Ravanello (2002). Analfabetismo e níveis de letramento no Brasil: O que dizem os censos?" Educação e Sociedade, Campinas, n. 23, v. 81, p. 21-47.

FERREIRA, Ana Paula (2009). Carolina in Black and White: Writing Race in Bondage. Philadelphia: MLA Convention

FREYRE, Gilberto (2003). Casa Grande e Senzala: Formação da Família Brasileira sob o Regime da Economia Patriarcal. São Paulo: Global.

GUIMARÃES, Antonio Sérgio Alfredo (2001). Democracia Racial: O Ideal, o Pacto e o Mito. Novos Estudos - CEBRAP, São Paulo, n. 61, p. 147-162, nov.

JAKOBSON, Roman (1987). On Linguistic Aspects of Translation (1933). In: POMORSKA, Krystina; RUDY, Stephen (Org.). Language in Literature: An Introduction to Stylistics. Cambridge, Mass.: Belknap P.

JESUS, Carolina Maria de (1961). Casa de alvenaria: diário de uma ex-favelada. Rio de Janeiro: Paulo de Azevedo.

JESUS, Carolina Maria de (1996). Meu estranho diário. Editado por Robert M. Levine, José Sebe Bom Meihy. São Paulo: Xamã.

JESUS, Carolina Maria de (1999). The unedited diaries of Carolina Maria de Jesus. Translated by Cristina Mehrtens and Nancy P. S. Naro. New Brunswick. New Jersey, London: Rutgers.

JESUS, Carolina Maria de (2003). Child of the dark. Translated by David St. Clair. New York: Dutton.

JESUS, Carolina Maria de (2007). Quarto de despejo: diário de uma favelada. São Paulo: Ática.

LEVINE, Robert M.; MEIHY, José Carlos Sebe Bom (1995). The life and death of Carolina Maria de Jesus. $1^{\text {st }}$ ed. Albuquerque: University of New Mexico.

MOTTA, Rodrigo Patto Sá (2002). Em guarda contra o "perigo vermelho": o anticomunismo no Brasil, 19171964. São Paulo: Editora Perspectiva, Fapesp.

NASCIMENTO, Abdias do (1978). O genocídio do negro brasileiro: processo de um racismo mascarado. Rio de Janeiro: Paz e Terra.

PERPÉTUA, Elzira Divina (2014). A vida escrita de Carolina Maria de Jesus. Belo Horizonte: Nandyala.

SANTOS, Zuleika Virgílio dos (2014). O desafio de Carolina Maria de Jesus: da invisibilidade à escritora de Quarto de despejo. Monografia (Licenciatura em Letras Português) - Instituto de Letras, Universidade de Brasília, Brasília. Disponível em: http://bdm.unb.br/handle/10483/8712. Acesso em: 31/05/2017.

SPIVAK, Gayatri Chakravorty (1994). Can the subaltern speak? In: WILLIAMS, Patrick; CHRISMAN, Laura (Org.). Colonial Discourse and Post-Colonial Theory: A Reader. New York: Harvester /Wheatsheaf, p. 66-111.

VENUTI, Lawrence (2004). The Translator's Invisibility: A History of Translation. London: Routledge. 